\title{
The MBA as Careerist: An Analysis of Early-Career Job Change
}

\author{
Thomas W. Dougherty \\ University of Missouri \\ George F. Dreher \\ Indiana University \\ William Whitely \\ University of Oklahoma
}

\begin{abstract}
This study examined the job changes of 680 early-career business school graduates. Although a number of anecdotal articles characterize MBAs as overly "careerist" and oriented toward jobhopping, little empirical research has focused on this issue. The research included a direct comparison of job-hopping behavior of $M B A s$ with bachelor's degree graduates, taking into account a number of control variables, including demographic and economic variables. Results indicated that $M B A s$ changed jobs less frequently than bachelor's degree graduates, even when a variety of other factors were controlled.
\end{abstract}

The proliferation of MBAs in managerial and professional jobs has been one of the most conspicuous trends in corporate America since the 1960s. A commonly cited statistic is the $21,000 \mathrm{MBA}$ graduates in 1970 that grew to 63,000 in 1983, to more than 70,000 in 1990 (Jenkins, Reizenstein, \& Rogers, 1984; Narisetti, 1991; Posner, 1987). Both MBA graduates and employing organizations portray the Master's in Business Administration degree as a powerful ticket to success. The career advantages of the MBA degree for the employee are documented in a number of research studies (Dreher, Dougherty, \& Whitely, 1985; Pfeffer, 1977). Among the advantages thought to accrue to firms that hire the MBA graduate are the obtaining of employees with a practical, "down-to-earth" orientation (compared to liberal arts graduates), savings in initial training costs, and the hiring of new employees already socialized in managerial and corporate values (Gannon \& Arlow, 1985). A steady stream of articles in popular business periodicals, however, casts doubt on the value of MBAs for organizations (e.g., Cheit, 1985; De Pasquale \& Lange, 1971; Gannon \& Arlow, 1985; Linden, 1992). MBAs have been characterized

Direct all correspondence to: Thomas W. Dougherty, University of Missouri, Department of Management, Columbia, MO 65211 .

Copyright 두 1993 by JAI Press Inc. 0149-2063 
as possessing undesirable traits such as unrealistic expectations, a rather crass, "careerist" orientation, and a tendency toward job-hopping. These tendencies are seen as seriously limiting the value of investments in employees who have received an $\mathrm{MBA}$ education. The present research focuses on the job-change behavior of a large group of MBA and bachelor's degree graduates from three large state universities to assess the extent of their early-career job-hopping.

Concern about excessive careerism and the resultant job-hopping among MBAs can be seen in a broader context as part of a tendency toward a "new careerism" among managers and professionals. As described by Feldman (1985), for example, contemporary careerist values have developed from lessened job security and more arbitrary and unpredictable treatment of employees by organizations. The new careerism includes employees' tendencies toward low organizational commitment, more turnover and "ticket-punching," self-absorption, and even unethical behavior (Feldman, 1985). Similarly, Luthans, Hodgetts, and Rosenkrantz's (1988) study of a large number of practicing managers confirmed a very real distinction between "successful" managers (velocity of promotion) and "effective" managers (high performers). Careerist managers who have achieved notable success in terms of promotions may not, in fact, be effective in their work.

An example of some of the particular stereotypes and perceptions of MBAs is provided by Cheit (1985), who presented an overview of criticisms of MBAs in reviewing 200 articles from journals, newspapers, and other sources. Among the four categories of complaints he identified is that MBAs possess undesirable attitudes - attitudes that are related to frequent changing of employers. Similar impressions were cited by De Pasquale and Lange (1971) in a widely cited Harvard Business Review article. They reported that the MBA "...has been criticized for a disposition to change jobs frequently, for an impatience to move ahead rapidly, and for a somewhat brash and exaggerated sense of self-worth" (p. 4). Another article commented about the expansive egos of MBAs and the difficulties companies have in finding appropriate spots for such overly ambitious people (Frakes, 1983). In like fashion, Gannon and Arlow (1985) reported the claim that $\mathrm{MBAs}$ are elitists and that increasing turnover among MBA graduates creates disillusionment on the part of the hiring organization.

The authors cited above represent a sampling of the conventional wisdom fueling skeptical comments about MBAs in the practitioner-oriented management literature. A smaller group of authors has challenged this conventional wisdom. Louis (1981), for example, also reviewed the criticisms of MBAs in the press. She referred to the criticisms as "stereotypes and mythmaking," citing a lack of evidence. She also pointed out that the label "MBA" is applied to diverse individuals earning the degree from more than 500 different schools. Her own data on MBAs (reported anecdotally) did not support myths such as the primacy of money in career decisions, MBAs planning concrete personal tracks to the top, and the tendency to be "career compulsives," sacrificing all other aspects of life for career interests. In a similar vein, Jenkins et al. (1984) reported the results of a survey of a sample of Fortune 500 CEOs and personnel directors, along with business school faculty and deans. Their 
results disconfirmed the dissatisfaction with MBA graduates conveyed in more impressionistic writings. They pointed out that CEOs were satisfied with MBAs' skills and attitudes in a variety of areas.

The scholarly literature of management contains little that lends direct support for predictions about MBA job change, but some evidence can be mustered to support both sides of the issue. First, recent meta-analyses of the turnover literature confirm that more educated employees are more likely to resign from their jobs (Cotton \& Tuttle, 1986). In addition, some indirect support for the view of MBAs as job hoppers is provided by the literature of organizational commitment, a construct consistently related to employee retention (Mowday, Porter, \& Steers, 1982). Several studies have found that organizational commitment tends to be lower for those with higher levels of education (Angle \& Perry, 1981; Morris \& Sherman, 1981; Morris \& Steers, 1980; Steers, 1977). These results are usually seen to be a result of the higher level of (unmet) expectations of those who have increased the value of their human capital with more education (Mowday et al., 1982). Other research has demonstrated that commitment declines when one experiences disconfirmed expectations (Buchanon, 1974).

Another rationale for expecting MBAs to change jobs frequently stems from their having developed a network of informal contacts. Granovetter (1974) contends that mobility appears to be "self-generating," in that people are able to stockpile their store of contacts. Thus, the more positions one holds, the more contacts one makes to enhance mobility. A commonly cited advantage of the MBA degree is the network of contacts provided to the graduate (Dreher et al., 1985). Granovetter (1974) also found that older workers are more likely to use personal contacts ("informal" strategies) in finding jobs. Thus, the older and more experienced MBAs should possess more informal sources of information and social influence to facilitate their mobility compared to those with bachelor's degrees.

Consideration of "human capital" theory also can support the expectation that MBAs engage in more job changing than bachelor's graduates (Becker, 1964). MBA training is "general" rather than "specific" training, and is not targeted to enhancing productivity in a particular job. The investment in general training is made by the person (versus the firm), and returns accrue to the person. To maximize return from the investment in education, the MBA may have to move. Similarly, the employer may lack the incentive to reduce the turnover of those who have not received the firm's investment in more specific training.

On the other hand, one might expect that MBAs possess certain qualities that would result in less job changing. Another stream of research that examines personal contacts and job change points to a different conclusion than that discussed above. This research has linked informal sources of hires (e.g., from networks of contacts) with lower turnover rates (Wanous \& Colella, 1989). The dominant explanation is that informal sources provide more realistic information to new employees, thus increasing the accuracy of expectations and enhancing the person-job match. Thus, the literature appears to contain 
contradictory findings concerning the impact of informal networks for job stability versus job change.

We might also expect MBAs to have developed considerable vocational maturity, in the sense of solidified career values and career focus. Using the terminology of Super (1969), MBAs are more likely to be in the "establishment" phase (26-45 years old) as opposed to the "exploration" phase of their careers. The establishment phase is characterized by fewer transitions, less tentativeness, and more commitment, compared with the exploration phase. Since MBAs have often gained work experience before receiving the degree, they are also likely to have achieved additional self-insight and a realistic appraisal of their skills, values, and needs. They should also be able to make more accurate diagnoses of potential job situations from incomplete or distorted information. This enables them to assess their "fit" with the organization culture (see Schein, 1978, pp. 86-89). Moreover, many MBA programs have developed special career development services, seminars, and placement centers (Cooper \& Dowd, 1987), which can assist in finding a job that is a good match. Thus, in entering organizations, MBAs might be expected to be more likely than others to identify work situations that are congruent with their talents, needs, and values.

Reports of empirical data specific to the job-hopping tendencies of MBAs, conducted for cohorts of MBAs graduating in the 1960s and 1970s, have produced less-than-convincing results. De Pasquale and Lange (1971) surveyed 5,022 MBA graduates from the 1965-68 classes of twelve leading business schools. They found that by the end of the third year out of the university, 34-37 percent of the graduates had departed from their original firms. This analysis, however, was conducted before occurrence of the largest increases in the popularity of the MBA and in the number of graduates. Conversely, an article in Fortune magazine reported a subsequent analysis of job change conducted by Louis, who studied 220 MBAs from the 1977 classes of Stanford, Berkeley, UCLA, and USC (Frakes, 1983). Within five years, two-thirds of the MBAs had left their first employer, and nearly 20 percent had switched twice.

These analyses are limited in several ways. Analysis of job changes of MBAs is difficult to interpret without any comparison groups. Specifically, without any direct comparisons with other groups graduating at the same time, conclusions about excessive MBA job-hopping must be considered as tentative and speculative. An adequate analysis of job-hopping also calls for some control variables, in order to take into account factors such as the type of job and the magnitude of beginning salary levels. These factors could account for jobchanging tendencies, regardless of one's status as an MBA graduate. The lack of comparison groups and control variables limits the ability to conduct precise analyses and draw firm conclusions about the job-change behavior of MBAs.

As a control variable, in the present study we included age, in that the turnover literature is consistent in finding that older employees are less likely to resign. Similarly, we included sex, marital status, and number of children, in that females are more likely to quit, while those who are married and those with more dependents are less likely to resign their jobs (cf. Cotton \& Tuttle, 1986; Mobley, 1982; Price, 1977). As additional control variables we included 
industry because there may be differences in job-changing for manufacturing versus service sector employers (Cotton \& Tuttle, 1986), and functional area because there could be turnover differences among those working in financial services, sales or purchasing, managerial, technical, or other professional positions. We also included starting salary as a control variable, in that those who feel underpaid will likely try to improve their circumstances.

There are also likely to be differences in labor market conditions for graduates of the 1980s, compared to earlier periods, such as the 1960s and 1970s, when the previous analyses were conducted. The dramatic increase in the supply of MBAs in the 1970s would be expected to crowd organizations, leaving fewer and fewer mobility opportunities in general. In addition, as a result of shifting demographic trends, adjacent age cohorts can differ considerably in their career opportunities, values and expectations, and organizational commitment (see Ahlburg \& Kimmel, 1986). For the present sample, the major economic downturn that began in 1981 and continued through most of 1982 most likely reduced mobility opportunities for young managers and professionals for a period of time. Thus, as an additional control variable, we also included the experience of recession for certain cohorts in our analysis. A recent study by Gerhart (1990) confirmed that economic conditions can have a direct effect on individuals' decisions to leave firms. We were also able to perform a partial analysis of job market opportunity for specific labor markets, and relate it to job change (Dreher \& Dougherty, 1980).

The purpose of the present study was to determine if a large sample of early-career MBA graduates changed jobs more frequently than a comparable group of bachelor's degree graduates. By controlling for a number of other variables potentially related to job change, we could perform a more precise analysis of job-hopping than those studies reported previously. The specific research question was:

After controlling for a variety of correlates of job change, do earlycareer MBA graduates change jobs more frequently than those with bachelor's degrees in business?

\section{Method}

\section{Sample and Procedures}

Using alumni records at the Universities of Kansas, Missouri, and Oklahoma, we surveyed all MBA program graduates from the classes of 19781982, four to five years after graduation. BSBA (Bachelor of Science in Business Administration) program graduates from the same years were randomly sampled so that the number of MBA and BSBA graduates surveyed was equivalent. Two waves of survey data were collected, one for 1978-1979 graduates, and one for 1980-82 graduates, such that all graduates had been out of the university for three to five years. Sample members received a questionnaire and a stamped return envelope. To encourage responses we promised sample members feedback of some basic results, including salary 
information. In addition, several weeks after the initial mailout a follow-up letter was sent to all sample members, urging them to complete their surveys and mail them. The survey response rates were 52 percent for both waves of data.

The data sets for both the 1978-1979 and the 1980-1982 groups have been analyzed in previous studies of other issues (Dreher et al., 1985; Whitely, Dougherty \& Dreher, 1991). These two data sets were combined to create a unique data set, resulting in a sample of 842 early-career managers and professionals. Although no detailed analysis of respondents versus nonrespondents was possible, the response rates were essentially the same between universities and between the MBA and BSBA groups. Half the sample were MBA graduates, and half were BSBA graduates. The average age for the entire sample was 29,28 percent of whom were females. These men and women worked in widely varying geographic locations, industries, and types of organizations.

For the analysis sample, we retained those who were working full-time at the time of data collection, who had not completed an additional degree subsequent to earning either their MBA or BSBA degree, and who were not self-employed or working in a family business. All analyses were performed for the 680 respondents with complete data on all variables.

\section{Measures}

The survey collected many types of information. The present study included the basic criterion variable (number of job changes), education (BSBA, $\mathrm{MBA}$ ), which was the predictor of interest, and a number of control variables for the analysis - factors potentially related to one's decision to change jobs. These control variables were included to allow for assessing the relationship of the MBA to job change, while ruling out a variety of other explanations.

Job changes, the criterion variable, was the number of times since graduation each respondent had moved to a different organization.

Control variables included age in years; sex, coded 0 for male and 1 for female; marital status, coded 0 for married and 1 for single; number of children, the number of dependent children living at home; years since graduation, ranging from 3 to 5 , depending upon graduation date; and industry, coded 0 for those in manufacturing firms and 1 for those in service firms. For respondent's functional area, four dummy variables were constructed, including financial services positions, sales-purchasing positions, managerialadministrative positions, and technical positions with "other professional" as the contrast group. Starting salary on one's first job after graduation was the dollar amount of salary earned. Because starting salary was measured in different years, price inflation for this measure posed a problem. To remove the inflation effect, we divided the starting salary figure by the gross national product price deflator, with $1982=1.00$ (Economic Report of the President, Feb. 1990, p. 298).

We also included a variable indicating whether these graduates had experienced periods of recession during the 3 to 5 years after graduation. A commonly accepted criterion for a recession is a third consecutive quarter of 
negative economic growth. All of the early-career cohorts in this study (19781982) except the 1982 group had experienced at least one-half year of recession in their careers since graduation, according to U.S. Department of Commerce data. Thus, we coded 1982 graduates as 0 (no recession) and the other groups as 1 (recession).

Degree, the primary predictor variable, was coded as 0 for BSBA and 1 for MBA degree earned.

\section{Analyses}

Data were analyzed via correlation and regression analysis. First, we assessed means, standard deviations, and zero-order correlations among variables. Next, we used multiple regression to assess the relationship of the MBA degree to job changes, with other factors statistically controlled.

\section{Results}

Using several different indices and analyses, results consistently indicated that bachelor's degree graduates had changed jobs more frequently than MBA graduates. First, the correlation of job change with degree was $r=-.17$ ( $p \geq$ .01 ), indicating more job changes for bachelor's degree graduates. The mean number of job changes was 9 for MBA graduates and 1.3 for bachelor's degree holders. For a more precise comparison, we also divided (for each person) the number of job changes by the number of years since graduation to obtain an index of "job changes per year." Bachelor's graduates averaged .32 job changes per year, while MB $\Lambda$ s had changed jobs .22 times. We also found that 70 percent of the bachelor's degree holders had changed jobs at least once, while 56 percent of the MBAs had done so.

Table 1 displays the means, standard deviations, and zero-order correlations among all variables studied. The results in Table 1 indicate that compared to BSBAs, MBA graduates also tended to be older, male, married, with more children, more likely to work in managerial jobs, less likely to work in financial services or sales-purchasing positions, and earned higher starting salaries. Inspection of the significant zero-order correlations in Table 1 indicates that job change was related to holding a bachelor's degree, being younger in age, employment in an "other professional" position rather than a managerialadministrative job, and earning a lower initial starting salary.

Table 2 reports the results of regression analysis. Number of job changes was regressed on the set of thirteen predictors, to determine which factors were related to job-hopping when other variables were statistically controlled. The table displays the standardized regression coefficients. Five variables were related to job change when the effects of other variables were removed: degree earned (bachelor's), working in a technical position, a lower starting salary, more years since graduation, and no experience of recession.

A factor that could confound an analysis of job changes is the amount of opportunity for getting a new job in one's particular labor market. This 


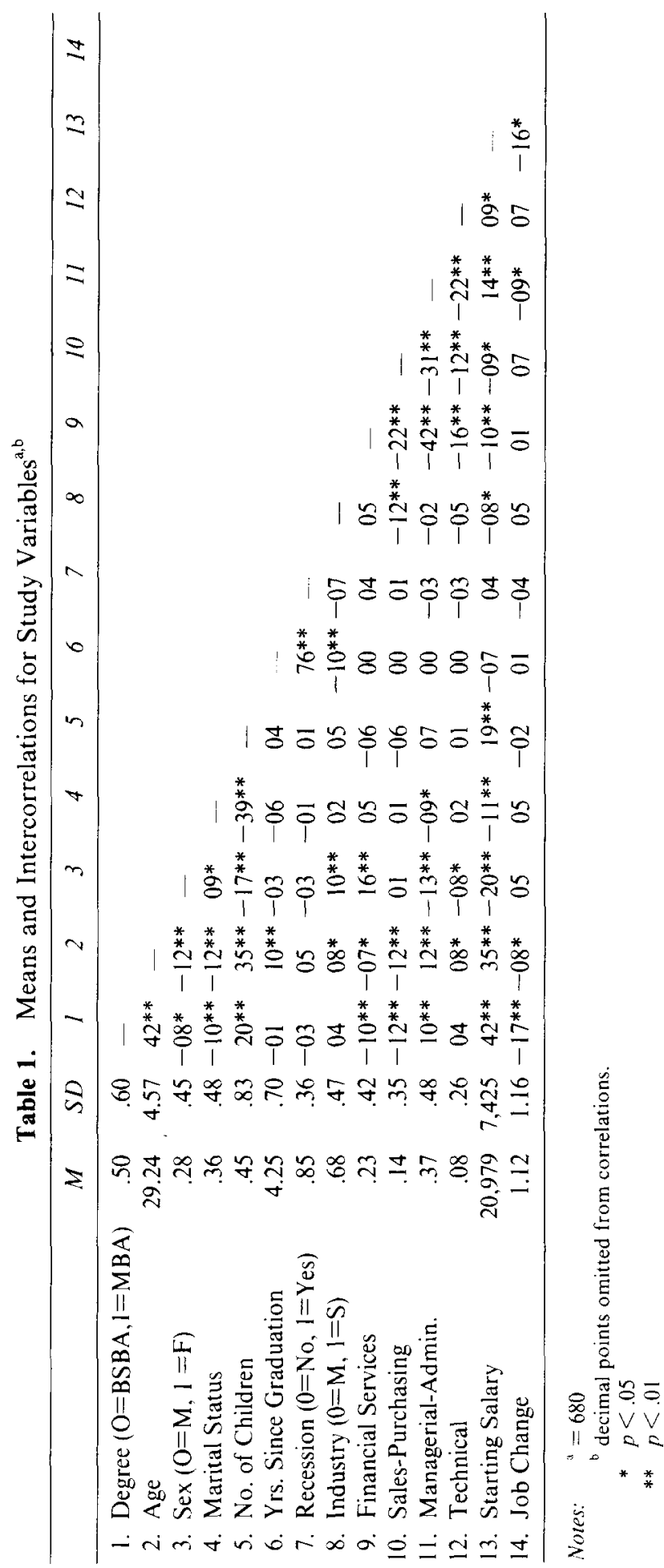


Table 2. Regression Of Job Change on Predictors ${ }^{\mathrm{a}}$

\begin{tabular}{|c|c|c|}
\hline \multicolumn{2}{|c|}{ Variable } & \multirow{2}{*}{$\frac{\text { Beta }}{.00}$} \\
\hline 1. & Age & \\
\hline 2. & $\operatorname{Sex}(0=M, 1=F)$ & .02 \\
\hline 3. & Marital Status $(0=M, 1=S)$ & .03 \\
\hline 4. & No. of Children & .05 \\
\hline 5. & Years Since Graduation & $.11^{*}$ \\
\hline 6. & Recession $(0=\mathrm{No}, 1=\mathrm{Yes})$ & $-.12 * *$ \\
\hline 7. & Industry $(0=\mathrm{M}, \mathrm{l}=\mathrm{S})$ & .05 \\
\hline 8. & Financial Services & .00 \\
\hline 9. & Sales-Purchasing & .05 \\
\hline & Managerial-Administrative & -.02 \\
\hline & Technical & $.08 *$ \\
\hline & Starting Salary & $-.12^{* *}$ \\
\hline 13. & Degree $(0=\mathrm{BSBA}, 1=\mathrm{MBA})$ & $-.12^{* *}$ \\
\hline
\end{tabular}

opportunity would likely vary according to occupational specialty. We were able to perform a partial assessment of this possibility. For 354 of the respondents (from the 1980-1982 group of graduates) it was possible to construct an index of "job market opportunity," using data available from the Bureau of Labor Statistics (BLS). The analysis was possible because this group of respondents had provided specific information about their occupational specialties. Following a procedure demonstrated previously in a study of turnover (see Dreher \& Dougherty, 1980), the index consisted of a scale from 1 to 5 , indicating the amount of labor market competition for each respondent's occupation during a particular time period. The scale values we assigned directly corresponded to the opportunity categories used by the BLS, such as "intense competition" and "excellent opportunities." The government data were national figures, appropriate for our sample, which was widely dispersed geographically. This measure represents an "interoccupational" variable, which avoids the restricted variance problem of many studies of perceived alternatives using occupationally homogeneous samples (Steel \& Griffeth, 1989).

We found that this market opportunity variable was not significantly related to number of job changes $(r=-.07$, n.s.) for this smaller group of 354 . In addition, we inserted job market opportunity as a variable in the completc regression equation to explain job change for this group $(n=246)$. Job opportunity was not significant. However, with market opportunity controlled, degree was still significant as a predictor of job change.

We also regressed the job market opportunity index on the set of four "functional area" variables in the study-financial services, sales-purchasing, managerial-administrative, and technical. The multiple correlation was $R=.62$, $p<.01$. This result indicates that the set of four functional area variables in 
our full analysis ( $n=680$ ) adequately controls for, or serves as a surrogate for, job market opportunity. Therefore, job market opportunity would not be expected to have accounted for the job change differences in our analysis.

To summarize, our results indicate that bachelor's degree graduates changed jobs more frequently than MBAs. This result held up with a number of other demographic and economic factors statistically controlled in the analysis. Thus, this difference cannot be accounted for by factors such as type of job, starting salary, or market opportunity.

\section{Discussion}

Although little empirical evidence existed, a number of articles in the popular management literature have decried the negative personal characteristics of graduates of MBA programs, especially their proclivity for job-hopping. These concerns can be placed in a broader context as concerns about a "new careerism" of job change, self-absorption, and lessened work commitment (Feldman, 1985). Our data for a large sample of graduates from three institutions do not support this concern. MBAs actually changed jobs less than a comparable group of bachelor's degree graduates during the same time period. Our results for these early-career managers and professionals held up even when a number of control variables were taken into account in regression analyses. Our analysis included variables representing both general economic conditions (recession) and job market opportunity for specific subgroups. These kinds of variables generally have been ignored and should be given more attention in studies of job change and career progress.

These results do not conform to the tendency in the turnover literature for education level to be related to turnover (Cotton \& Tuttle, 1986). However, the present study included only employees who had achieved at least a bachelor's degree, which is somewhat different from analyses of a wide range of education levels. The overall amount of job changing for the MBAs in the present study was also lower than in previous studies of MBAs, such as the job change data in the study by Louis (Frakes, 1983). Of the MBAs in the present study, 56 percent had changed jobs within the three- to five-year period after graduation, while in the Louis study, two-thirds of the sample of $1977 \mathrm{MBA}$ graduates from Stanford, Berkeley, UCLA and USC had changed jobs within five years. A direct comparison, however, is difficult because of differences in economic conditions and in the number of MBAs in the labor market during the particular time periods of the studies.

A related issue, which is important for the generalizability of the results, concerns the nature of the present sample of MBAs. The graduates in our study were not from "top 10" or the highest prestige MBA programs. It is possible that some of the widely advertised "careerist" characteristics of MBAs exist to a greater extent in graduates of elite programs. However, two of the three programs included in our study had typically been ranked within the top 45 MBA programs in the U.S. (Gourman, 1980). The graduates and the programs of these three state universities have many characteristics in common with a 
large number of graduates and MBA programs around the country. In this sense, the results should be generalizable. Nevertheless, future studies using more diverse samples, including private and public schools, both high and moderate status programs, and diverse geographic locations could provide a more comprehensive analysis of job change and other early career issues.

Another potential problem in interpretation of our results would be the occurrence of "employer-funded" graduates in our sample. If some of our study participants had been sponsored by their employers while earning their degree, they may have been formally or informally bound to remain with those employers. Thus employer-funded graduates might be less likely to change jobs. Consulting with university officials, we learned that no BSBA graduates at these universities were employer-funded. Next, considering MBA graduates, we learned that Kansas had a part-time urban program which contributed 15 percent of the graduates from 1978-1982, some of whom may have been employer-funded. Similarly, Oklahoma officials reported that some percentage less than 15 percent were potentially employer-funded. At Missouri, officials reported that virtually none of the 1978-1982 MBAs were employer-funded. Thus, some unknown, but small percentage of our MBA sample may have received employer-funding; the upper bound possibility would be 10 percent of the total MBA sample.

In addition, we learned that even though 15 percent of the Kansas MBAs were part-time students, there was a miniscule number of part-timers in the 1978-1979 Kansas graduation groups. We compared the ratio of MBA/BSBA job change for the 1978-1979 group (0-5 percent part-timers) with the ratio for 1980-1982 graduates (18-21 percent part-timers). We found very similar ratios of MBA to BSBA job change for the two groups, suggesting that employerfunding was not an important factor in our job change results.

We also acknowledge that the variables in our study did not account for a large portion of the variance in job change $\left(R=.25, R^{2}=.06\right)$. However, to put this in perspective, typical studies of employee turnover often produce similar magnitudes of relationships (Mobley, 1982). Further, predictive relationships of this magnitude may still have practical utility for organizations.

Rescarch focusing more dircetly on the experiences, attitudes, and job changes of early-career MBAs could provide useful information, both for scholars and practitioners. Study of these processes probably would not be dominated by a focus on maladaptive values or personal traits of the MBAs themselves. Louis (1981), for example, has suggested that MBAs experience disillusionment when faced with (a) employers' resistance to change and innovative ideas, (b) political realities, personal motives, and multiple agendas in modern-day organizations, and (c) broken promises from employers. These comprise some interesting avenues for research on job change and on the experiences of managerials and professionals as they enter organizations to begin their careers. Similarly, Rousseau (1990) recently pointed out the lack of empirical research on perceived obligations in employment. She found that beliefs about employee and employer obligations are linked with a new hire's opportunistic ("careerist") orientation, viewing johs as stepping-stones to jobs 
in other organizations. Perceived obligations in the initial employment contract is a fruitful area for future research on job change and career processes.

In addition, we have suggested that MBAs may possess a stronger sense of career values and maturity compared to other types of hires. It is interesting to note that for a portion of our total sample (the 1980-1982 graduates) we had collected a measure of work centrality, which was the number of points (out of 100) assigned to "work" versus four other facets of one's life (MOW International Research Team, 1987). Work centrality was significantly correlated with degree $(r=.16, p<.01)$, indicating that work was more central in the lives of MBA (compared to bachelor's) graduates. Work centrality was not significantly related to job change, however, in this subsample. Greater work centrality and involvement is also a major factor in what Hall and Nougaim (1968) termed the "success syndrome" and can be a factor in improving internal promotion opportunities, thus reducing external mobility. The issue of work commitment and job involvement of early-career employees should be pursued further, especially in light of recent concerns about new styles of careerism, and mangers who are "successful" but not effective (Feldman, 1985; Luthans et al., 1988).

The role of non-work factors, including family variables, should also receive additional attention in research on early careers and job change. In the present study, we found no relationships of sex, marital status, or number of children with job change. Kram (1985) has suggested that one's "relationship constcllation" includes family, subordinatcs, supcrvisors, peers, and outside-ofwork friends. An inadequate relationship constellation can result in stress, alienation, and dissatisfaction with work. The role of mentoring, relationship constellations, and other interpersonal support systems in employees' job changing represents a potentially fruitful avenue of research.

Some recent research also suggests that a number of "non-ability" factors may be important for the early-career experience of managers and professionals. These studies suggest that although it is often assumed that ability and achievement determine cmployecs' carcer progress, factors such as socioeconomic background, political influence tactics, and career mentoring may also be important for career success (Dreher et al., 1985; Dreher, Dougherty, \& Whitely, 1989; Pfeffer, 1977; Whitely et al., 1991). Pursuing these areas should provide insights into job change and career mobility as well.

From a practical standpoint, employers may be well-advised to focus their attention primarily on the job-relevant background and skills they seek in hiring new managers and professionals from the ranks of business schools. There is little evidence to date that MB $\Lambda$ graduates, as an aspect of their training or socialization, present a worrisome tendency to expect too much, to be brash and uncompromising, and to engage in excessive job-hopping. We can expect that these graduates will be more likely to demonstrate a strong sense of work values, career maturity and stability - qualities highly prized by most employers.

Acknowledgment: The authors wish to thank Daniel Turban and two anonymous reviewers for their comments and suggestions for revising earlier 
drafts. We also acknowledge financial support from the Ponder Faculty Development and Research Fund, College of Business and Public Administration, University of Missouri.

\section{References}

Ahlburg, D. A. \& Kimmel, L. (1986). Human resources management implications of changing age structure in the U.S. labor force. Pp. 339-374 in K.M. Rowland \& G.R. Ferris (Eds.), Research in personnel and human resources management, Vol. 4. Greenwich, CT: JAI.

Angle, H. \& Perry, J. (1981). An empirical assessment of organizational commitment and organizational effectiveness. Administrative Science Quarterly, 26: 1-14.

Becker, G. S. (1964). Human capital: A theoretical and empirical analysis, with special reference to education. New York: National Bureau of Economic Research.

Buchanon, B. (1974). Building organizational commitment: The socialization of managers in work organizations. Administrative Science Quarterly, 19:533-546.

Cheit, E. F. (1985). Business schools and their critics. California Management Review, (Spring): 43-61.

Cooper, C. \& Dowd, K. (1987). Mid-life crisis for the MBA. Management Today, (April): $81-86$.

Cotton, J. L. \& Tuttle, J. M. (1986). Employee turnover: A meta-analysis and review with implications for research. Academy of Management Review, 11: 55-70.

De Pasquale, J. A. \& Lange, R. A. (1971). Job-hopping and the MBA. Harvard Business Review, (November/ December): 4-10, 151-154.

Dreher, G. F. \& Dougherty, T. W. (1980). Turnover and competition for expected job openings: An exploratory analysis. Academy of Management Journal, 23: 766-772.

Dreher, G. F., Dougherty, T. W., \& Whitely, B. (1985). Generalizability of MBA degree and socioeconomic effects on business school graduates' salaries. Journal of Applied Psychology, 70: 769-773. 550 .

Economic Report of the President. (1990). Washington, DC: United States Government Printing Office.

Feldman, D. C. (1985). The new careerism: Origins, tenets, and consequences. The Industrial-Organizational Psychologist, 22(4): 39-44.

Frakes, S. (1983). Tough times for MBAs. Fortune, (Dec. 12): 65-72.

Gannon, M. J. \& Arlow, P. (1985). The mystique of the MBA degree. Business Horizons, 28(1): 20-25.

Gerhart, B. (1990). Voluntary turnover and alternative job opportunities. Journal of Applied Psychology, 75: $467-476$.

Gourman, J. (1980). The Gourman report: A rating of graduate and professional programs in American and international universities. Los Angeles: National Education Standards.

Granovetter, M. S. (1974). Getting a job: A study of contacts and careers. Cambridge, MA: Harvard University Press.

Hall, D. T. \& Nougaim, K. (1968). An examination of Maslow's need hierarchy in an organization setting. Organizational Behavior and Human Performance, 3: 12-35.

Jenkins, R. L., Reizenstein, R. G., \& Rogers, F. G. (1984). Report cards on the MBA. Harvard Business Revien, (September/October): 20-30.

Kram, K. E. (1985), Mentoring at work: Developmental relationships in organizational life. Glenview, IL: Scott, Foresman.

Linden, D. W. (1992). Another boom ends. Forbes, 149(2): 76-80.

Louis, M. R. (1981). MBAs in the press: Stereotypes and mythmaking. The Wharton Magazine, (Fall): 1218.

Luthans, F., Hodgetts, R. M., \& Rosenkrantz, S. A. (1988). Real managers. Cambridge, MA: Ballinger.

Mobley, W. H. (1982). Employee turnover: Causes, consequences, and control. Reading, MA: AddisonWesley.

Morris, J. \& Sherman, J. D. (1981). Generalizability of an organizational commitment model. Academy of Management Journal, 24: 512-526.

Morris, J.\& Steers, R. M. (1980). Structural influences on organizational commitment. Journal of Vocational Behavior, 17: 50-57.

MOW International Research Team. (1987). The meaning of working. New York: Academic Press.

Mowday, R. T., Porter, I. W., \& Steers, R. M. (1982). Emplovee-organization linkages: The psychology' of commilment, absenteeism, and turnover. New York: Academic Press.

Narisetti, R. (1991). Business schools revamp to win students. Wall Street Journal, (August 21): B1, B4.

Pfeffer, J. (1977). Effects of an MBA and socioeconomic origins on business school graduates'salaries. Journal of Applied Psychology, 62: 698-705. 
Posner, B. G. (1987). Breaking away. Inc., (June): 52-62.

Price, J. L. (1977). The study of iurnover. Ames, IA: I he lowa State University Press.

Rousseau, D. M. (1990). New hire perceptions of their own and their employer's obligations: A study of psychological contracts. Journal of Organizational Behavior, 11:389-400.

Schein, E. H (1978). Career dynamics: Matching individual and organizational needs. Reading, MA: Addison-Wesley.

Steel, R. P. \& Griffeth, R. W. (1989). The elusive relationship between perceived employment opportunity and turnover behavior: A methodological or conceptual artifact? Journal of Applied Psychology, 74: 846-854.

Steers, R. M. (1977). Antecedents and outcomes of organizational commitment. Administrative Science Quarterly, 22: 46-56.

Super. D. E. (1969). The natural history of a study of lives and vocations. Perspectives on Education, 2 : 13-22.

Wanous, J. P. \& Colella, A. (1989). Organizational entry research: Current status and future directions. Pp. $59-120$ in G.R. Ferris \& K.M. Rowland (Eds.), Research in personnel and human resources manugement, Vol. 7. Greenwich, CT: JAI.

Whitely, W., Dougherty, T. W., \& Dreher, G. F. (1991). The relationship of career mentoring and socioeconomic origin to managers' and professionals' early-career progress. Academy of Management Journal, 34: 331-351. 